\title{
sciendo
}

\section{A New Approach to the Analysis of Pitch-Positions in Professional Soccer}

\author{
by \\ Marek Konefat1, Pawet Chmura², Tomasz Zajac ${ }^{3}$, Jan Chmura ${ }^{1}$, Edward Kowalczuk ${ }^{4}$, \\ Marcin Andrzejewski ${ }^{5}$
}

\begin{abstract}
The purpose of the study was to examine how various playing positions affected the number of (and percentage breakdowns for) physical and technical activities of soccer players in the Germany's Bundesliga. A further objective was to identify and present features distinguishing between the activities of players within the Defender, Midfielder and Forward formations. The study sample comprised 4426 individual match observations of 473 soccer players competing in the Bundesliga during the 2016/2017 domestic season. Data from the Impire AG motion analysis system, and the socalled "heat maps" it supplies, revealed areas in which players spent most time during a match, with 22 different playing positions on the pitch identified in consequence. Players in the formation comprising Defenders did not differ significantly in relation to the number of accelerations, the number of shots or the percentage of duels won. Furthermore, there were no significant differences among Midfielders in regard to total distance covered, mean running speed, the number of accelerations, the number of duels and the percentage of duels won. Likewise, Forwards did not differ in distances covered at $\geq 24 \mathrm{~km} / \mathrm{h}$, average running speed, the number of sprints, the number of shots, the proportion of on-target passes, the number of duels, or the percentage share of duels won. Irrespective of the formation or position on the pitch, today's game of soccer also pays great importance to the number of accelerations, as well as the number of duels engaged in, and their effectiveness.
\end{abstract}

Key words: game analysis, playing positions, physical activity, technical activity.

\section{Introduction}

The essence of soccer match-play comprises multi-directional physical activities integrated with an array of technical skills (Bradley et al., 2009; Wallace and Norton, 2014). Complexity is increased further as these activities are highly individualised and also likely to change every 4-6 s (Krustrup et al., 2005). For such reasons, efforts to improve strategy should draw on both detailed, individualised observation, and feedback for players and coaches (Wright et al., 2013). Contemporary notation analysis conducted

with this aim in mind may now use very precise data from technologically-advanced motion analysis systems (Hoppe et al., 2015; Konefał et al., 2015), and these are already seen to have many applications in research on the professional game of soccer. Above all, it is possible to assess movements of players that are either motorrelated, technical or tactical (Bradley et al., 2013; Konefał et al., 2018).

While physical and technical indicators may be perceived as separate aspects of the game,

\footnotetext{
1 - Department of Biological and Motor Sport Bases, University School of Physical Education, Wrockaw, Poland.

2 - Department of Team Games, University School of Physical Education, Wrocław, Poland.

3 - Performance Human Laboratory, Jerzy Kukuczka Academy of Physical Education, Katowice, Poland.

4 - Football Club, Hannover 96, Hannover, Germany.

5 - Department of Recreation, University School of Physical Education, Poznań, Poland.
} 
it seems that success in soccer in fact depends on tactics embracing appropriate levels of both (Mackenzie and Cushion, 2013). Nevertheless, scientists analysing activities of soccer players have often adopted a reductionist approach, presenting indices separately (Mackenzie and Cushion, 2013). The literature thus includes much data describing in detail activity that is either physical (Andrzejewski et al., 2018), or technical (Bradley et al., 2013).

When soccer's physical activities are concerned, the modern game's most important elements include total distance covered, distance covered at very high intensity, the number of sprints, and peak running speed (Chmura et al., 2018). The importance of these variables is underlined by the fact that, at the 2014 World Championships, the German national team covered a significantly greater total distance $(\mathrm{p} \leq$ $0.05)$, as well as a significantly greater distance at high intensity ( $p \leq 0.001)$, than other teams participating (Chmura et al., 2017).

Moreover, logistic models based on the most recent seasons in the German Bundesliga show that an average distance covered at speed greater by $0.1 \mathrm{~km}$ is associated with a probability of ultimate victory, which is $31.7 \%$ higher, while one extra first-half sprint on average raises that same probability by $8.6 \%$ (Konefał et al., 2018).

In contrast, among the many measures of technical activity, those regarded as most significant in soccer are numbers of shots and passes, pass accuracy and the number of duels won (Link and Lorenzo, 2016; Liu et al., 2015). Among teams reaching the quarter-finals of Euro 2012, the mean numbers of shots per match reached $16.83 \pm$ 7.65 , with $6.66 \pm 4.63$ shots on target; while the ultimate champions of the tournament completed $676.6 \pm 112$ passes on average, achieving passing accuracy of $88.46 \pm 2.32 \%$ (Shafizadeh et al., 2013).

A defined relationship between physical and technical activities has often been demonstrated. While the former have not been found to link directly with success, they do influence technical efficiency, and this differentiates between particular league rankings and/or competition standards in elite soccer (Carling, 2013). Technical activities are nevertheless more important than physical ones, since they have a more significant effect on the team's success (Carling, 2013; Castellano et al.,
2012; Di Salvo et al., 2013; Hoppe et al., 2015).

When match activities have been analysed in line with various playing positions, team success seems to depend on greater physical activity in some positions, and greater technical activity in others (Di Salvo et al., 2013). For example, Central Midfielders are responsible for most passes, while also achieving greatest effectiveness with those passes; and Forwards take the most shots during a match, and achieve highest efficiency (Bradley et al., 2013). Wide Midfielders' effectiveness of play is in turn linked to the distance covered at very high intensity (Konefał et al., 2018), while an effective Fullback achieves a greater total sprint distance (Andrzejewski et al., 2018).

The most recent studies on soccer players characterise activities among centre, right or left Defenders, centre, right or left Midfielders, or sometimes offensive or defensive Strikers (Andrzejewski et al., 2018; Chmura et al., 2018). Furthermore, the dynamic evolution of soccer quickly leaves analyses of team formations out of date, given a constantly changing strategy and playing style among teams, as well as more and more modern, precise observation systems (Bradley et al., 2016).

A more-detailed look at the physical and technical requirements set for players in different real-life positions thus seemed warranted as, notwithstanding complex interactions between physical and technical indices in elite soccer, studies revealing major differences between positions on the pitch have not yet been forthcoming. In light of this, we examined how various playing positions affected the number and the percentage of physical and technical activities among players of the German Bundesliga. The secondary aim was to compare activities in Defender, Midfielder and Forward formations.

\section{Methods}

\section{The Experimental Approach to the Problem}

The initial hypothesis was that players' positions on the pitch during a game determined the number of different physical and technical activities, and the percentage of all activities each accounted for. Statistically significant relationships between positions on the pitch during a game and the physical and technical activities analysed were assumed to exist. 


\section{Participants}

The study sample comprised 4426 individual match observations of 473 soccer players competing in the Bundesliga during the 2016/2017 season. Only players who completed entire matches (i.e. were on the pitch for the whole 90 minutes) were analysed. 22 different playing positions (Tiedemann et al., 2011) were distinguished on the basis of "heat map" data from the Impire AG motion analysis system, in relation to areas on the pitch in which given players spent most time (Figure 1). These players were further classified in terms of 22 positional roles, with account taken of three formations of outfield players, i.e. Defenders (2041 match observations) as Left Fullbacks (LFB, 400 match observations), Central Left Defenders (CLD, 564 match observations), Central Defenders (CD, 136 match observations), Central Right Defenders (CRD, 559 match observations) and Right Fullbacks (RFB, 382 match observations); Midfielders (1789 match observations) - Defensive Midfielders Left (DML, 346 match observations), Defensive Midfielders Central (DMC, 84 match observations), Defensive Midfielders Right (DMR, 316 match observations), Left Wide Midfielders (LWM, 224 match observations), Half Left Midfielders (HLM, 88 match observations), Central Midfielders (CM, 54 match observations), Half Right Midfielders (HRM, 72 match observations), Right Wide Midfielders (RWM, 192 match observations), Offensive Midfielders Left (OML, 146 match observations), Offensive Midfielders Central (OMC, 130 match observations), and Offensive Midfielders Right (OMR, 137 match observations); and Forwards (596 match observations) - Central Withdrawn Forwards (CWF, 36 match observations), Left Forwards (LF, 46 match observations), Half Left Forwards (HLF, 119 match observations), Central Forwards (CF, 215 match observations), Half Right Forwards (HRF, 129 match observations), and Right Forwards (RF, 51 match observations) (Figure 1).

Players' mean body height was $184.03 \pm$ $7.23 \mathrm{~cm}$, mean body mass $78.11 \pm 7.12 \mathrm{~kg}$, and mean age $26.52 \pm 4.01$ years.

The study was conducted in compliance with the Declaration of Helsinki and was approved by the Local Ethics Committee (No. 20/2017).

\section{Design and Procedures}

The analysis was carried out using the Impire AG motion analysis system (Tiedemann et al., 2011), with records of all players' movements in all the 918 matches, at a sampling frequency of 25 Hz. Impire AG (Ismaning, Germany) and Cairos Technologies AG (Karlsbad, Germany) provide a ready-to-use vision-based tracking system for team sports called VIS.TRACK. This consists of two cameras and software, tracking both the players and the ball. The major advantages of vision-based systems are their high update rate corresponding to the camera frame rate, and the fact that the players and the ball are tracked simultaneously, denoting therefore that each position sample for a single player has a corresponding position sample for every other player including the ball measured at the identical point in time. The validity and reliability of this system for taking such measurements have been described in detail elsewhere (Siegle et al., 2013; Tiedemann et al., 2011). Furthermore, Liu et al. (2013) showed that team match events coded by independent operators using this system achieved a very high level of agreement (weighted kappa values were 0.92 and 0.94 ), while the average difference characterising event times was $0.06 \pm$ $0.04 \mathrm{~s}$.

The system records the following physical activities of players: Total distance covered (TD) $[\mathrm{km}]$, Distance covered at $\geq 24 \mathrm{~km} / \mathrm{h}$ (VHIR) [km], Average running speed (ARS) $[\mathrm{km} / \mathrm{h}]$, Peak running speed (PRS) $[\mathrm{km} / \mathrm{h}]$, Total number of sprints (SN) [number] - (runs with a speed higher than $22.68 \mathrm{~km} / \mathrm{h}$ and at least one second in duration), and Acceleration (ACC) [number] - a positive acceleration value in each individual frame for at least $1.5 \mathrm{~s}$ (= tempo increase compared to the frame one second before).

The recorded technical activities of players include: Shots (S) [number], Passes (PN) [number], Pass Accuracy (PA) [\%], Duels (D) [number] where a duel involves two players of different teams in competition for the ball, and is therefore always assigned to both participant players, Duels won (DW) [\%], and Crosses (C) [number]. Complete definitions of technical activity are to be found at DFL. Definitionskatalog Offizielle Spieldaten. Definitions for Official Gama Data. Frankfurt (2014).

For a better depiction of differences in the 
occurrence of physical and technical activities among players in different pitch-positions, it was decided to compare all results with the arithmetic means characterising the three main Formations of Defenders, Midfielders and Forwards. Subsequently, these arithmetic means were the basis for seeking activity in any of the 22 analysed positions that was found to occur at a significantly higher or lower frequency.

\section{Statistical analysis}

All variables were examined for normal distribution (the Shapiro-Wilk test) and homogeneity of variance (the Levene's test). Arithmetic means and standard deviations were calculated, and then compared using one-way analysis of variance (ANOVA). The independent variables used were playing positions on the pitch, while the dependent variables included the selected technical activities described in the context of the study. Where significant effect size was noted, a post-hoc Fisher's LSD test was performed. Moreover, Cohen's (d) was calculated, and the effect sizes described in line with the following assumptions $\leq 0.35$ - small effect size; $>0.35$ and $<0.65$ - medium effect size, $\geq 0.65$ - large effect size (Cohen, 1988; Maszczyk et al., 2012, 2016). All statistical analyses were performed using the STATISTICA ver. 13.1 (StatSoft. Inc., the USA) software package.

\section{Results}

Tables 1-3 show analysis of variance models for the three main formations of Defenders, Midfielders and Forwards. Selected physical and technical activities among German Bundesliga soccer players are shown in the context of playing positions on the pitch. The ANOVA results with statistically significant differences and effect sizes are presented in what follows, in relation to different physical and technical activities.

Figure 1

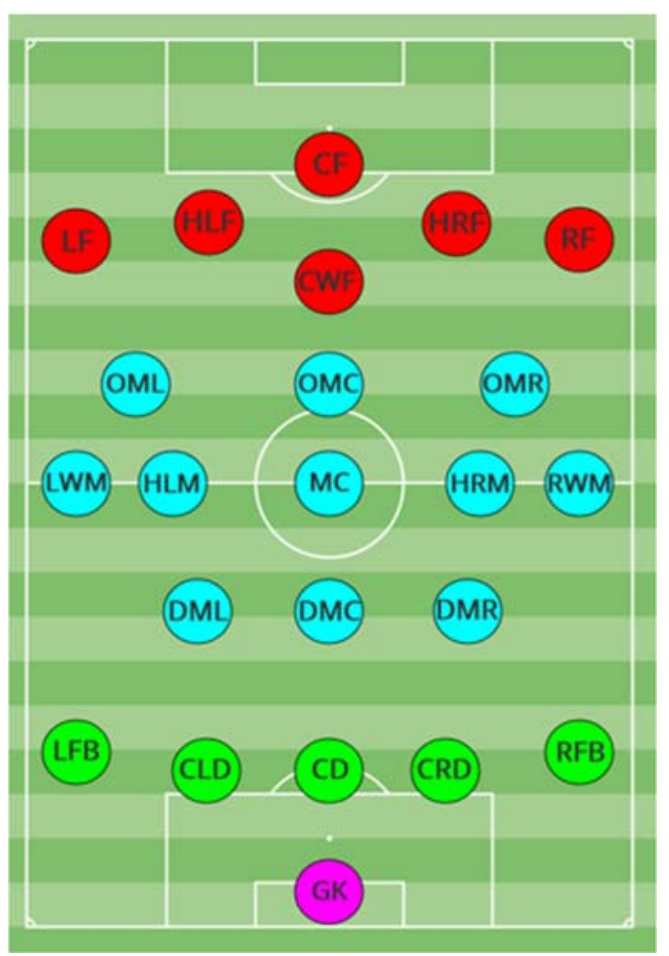

The 22 different playing positions identified on the pitch (on the basis of the Impire AG motion analysis system). 


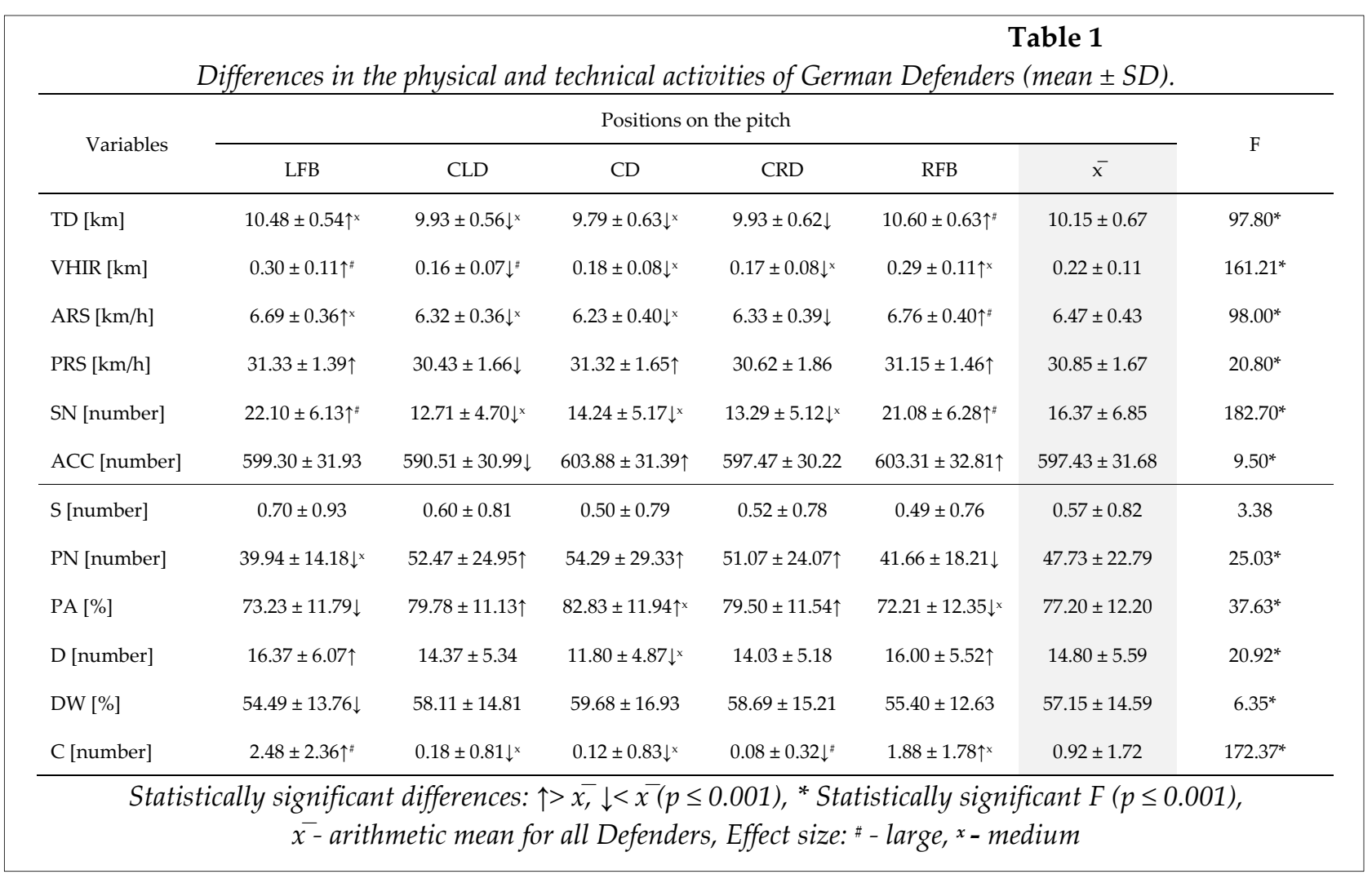

\begin{tabular}{|c|c|c|c|c|c|c|c|c|c|c|c|c|c|}
\hline \multirow{3}{*}{ Variables } & \multicolumn{13}{|c|}{$\begin{array}{c}\text { Table } 2 \\
\text { Differences in the physical and technical activities of German Midfielders (mean } \pm \text { SD). }\end{array}$} \\
\hline & \multicolumn{12}{|c|}{ Positions on the pitch } & \multirow{2}{*}{ F } \\
\hline & DML & DMC & DMR & LWM & HLM & $\mathrm{CM}$ & HRM & RWM & OML & OMC & OMR & $\bar{x}$ & \\
\hline $\mathrm{TD}[\mathrm{km}]$ & $\begin{array}{c}11.41 \uparrow \\
\pm 0.68\end{array}$ & $\begin{array}{l}11.31 \\
\pm 0.52\end{array}$ & $\begin{array}{l}11.34 \\
\pm 0.67\end{array}$ & $\begin{array}{c}11.03 \downarrow \\
\pm 0.65\end{array}$ & $\begin{array}{c}11.58 \uparrow^{x} \\
\pm 0.62\end{array}$ & $\begin{array}{l}10.98 \\
\pm 0.62\end{array}$ & $\begin{array}{l}11.49 \\
\pm 0.68\end{array}$ & $\begin{array}{l}11.10 \\
\pm 0.84\end{array}$ & $\begin{array}{c}10.84 \downarrow^{x} \\
\pm 0.68\end{array}$ & $\begin{array}{c}11.74 \uparrow^{x} \\
\pm 0.77\end{array}$ & $\begin{array}{l}11.07 \\
\pm 0.72\end{array}$ & $\begin{array}{l}11.27 \\
\pm 0.73\end{array}$ & $18.10^{*}$ \\
\hline $\begin{array}{l}\text { VHIR } \\
{[\mathrm{km}]}\end{array}$ & $\begin{array}{l}0.20 \downarrow^{x} \\
\pm 0.09\end{array}$ & $\begin{array}{l}0.16 \downarrow^{\sharp} \\
\pm 0.08\end{array}$ & $\begin{array}{l}0.19 \downarrow^{\sharp} \\
\pm 0.09\end{array}$ & $\begin{array}{l}0.35 \uparrow^{x} \\
\pm 0.12\end{array}$ & $\begin{array}{c}0.25 \\
\pm 0.11\end{array}$ & $\begin{array}{l}0.15 \downarrow^{\sharp} \\
\pm 0.07\end{array}$ & $\begin{array}{c}0.28 \\
\pm 0.14\end{array}$ & $\begin{array}{l}0.37 \uparrow^{\sharp} \\
\pm 0.13\end{array}$ & $\begin{array}{l}0.34 \uparrow^{x} \\
\pm 0.14\end{array}$ & $\begin{array}{c}0.26 \\
\pm 0.11\end{array}$ & $\begin{array}{l}0.37 \uparrow^{\sharp} \\
\pm 0.12\end{array}$ & $\begin{array}{c}0.27 \\
\pm 0.13\end{array}$ & $65.32^{*}$ \\
\hline $\begin{array}{l}\text { ARS } \\
{[\mathrm{km} / \mathrm{h}]}\end{array}$ & $\begin{array}{l}7.26 \\
\pm 0.43\end{array}$ & $\begin{array}{c}7.21 \\
\pm 0.34\end{array}$ & $\begin{array}{c}7.23 \\
\pm 0.44\end{array}$ & $\begin{array}{l}7.02 \downarrow^{x} \\
\pm 0.40\end{array}$ & $\begin{array}{l}7.40 \uparrow^{\times} \\
\pm 0.38\end{array}$ & $\begin{array}{c}7.04 \\
\pm 0.40\end{array}$ & $\begin{array}{c}7.35 \\
\pm 0.42\end{array}$ & $\begin{array}{c}7.09 \\
\pm 0.54\end{array}$ & $\begin{array}{l}6.90 \downarrow^{x} \\
\pm 0.44\end{array}$ & $\begin{array}{l}7.47 \\
\pm 0.51\end{array}$ & $\begin{array}{l}7.03 \downarrow \\
\pm 0.47\end{array}$ & $\begin{array}{l}7.18 \\
\pm 0.47\end{array}$ & $18.50^{*}$ \\
\hline $\begin{array}{l}\text { PRS } \\
{[\mathrm{km} / \mathrm{h}]}\end{array}$ & $\begin{array}{c}29.96 \downarrow^{x} \\
\pm 1.67\end{array}$ & $\begin{array}{c}29.89 \downarrow^{\mathrm{x}} \\
\pm 1.83\end{array}$ & $\begin{array}{c}30.04 \downarrow^{\mathrm{x}} \\
\pm 1.66\end{array}$ & $\begin{array}{c}31.45 \uparrow^{x} \\
\pm 1.34\end{array}$ & $\begin{array}{l}30.19 \\
\pm 1.41\end{array}$ & $\begin{array}{l}29.98 \\
\pm 1.56\end{array}$ & $\begin{array}{r}30.42 \\
\pm 1.69\end{array}$ & $\begin{array}{c}31.82 \uparrow^{\sharp} \\
\pm 1.53\end{array}$ & $\begin{array}{c}31.65 \uparrow^{x} \\
\pm 1.65\end{array}$ & $\begin{array}{l}30.34 \\
\pm 1.42\end{array}$ & $\begin{array}{c}31.81 \uparrow^{\sharp} \\
\pm 1.36\end{array}$ & $\begin{array}{l}30.71 \\
\pm 1.75\end{array}$ & $36.40^{*}$ \\
\hline $\begin{array}{l}\text { SN } \\
\text { [number] }\end{array}$ & $\begin{array}{c}16.65 \downarrow^{x} \\
\pm 5.83\end{array}$ & $\begin{array}{c}14.05 \downarrow " \\
\pm 5.31\end{array}$ & $\begin{array}{c}15.34 \downarrow^{*} \\
\pm 5.47\end{array}$ & $\begin{array}{c}25.18 \uparrow^{*} \\
\pm 6.37\end{array}$ & $\begin{array}{l}20.39 \\
\pm 6.72\end{array}$ & $\begin{array}{l}11.63 \downarrow^{\sharp} \\
\pm 4.42\end{array}$ & $\begin{array}{l}20.67 \\
\pm 8.45\end{array}$ & $\begin{array}{c}25.90 \uparrow^{\sharp} \\
\pm 7.36\end{array}$ & $\begin{array}{c}24.55 \uparrow^{x} \\
\pm 7.36\end{array}$ & $\begin{array}{l}21.20 \\
\pm 6.56\end{array}$ & $\begin{array}{c}26.63 \uparrow^{*} \\
\pm 6.84\end{array}$ & $\begin{array}{l}20.44 \\
\pm 7.88\end{array}$ & $65.14^{*}$ \\
\hline $\begin{array}{l}\text { ACC } \\
\text { [number] }\end{array}$ & $\begin{array}{l}617.90 \uparrow \\
\pm 30.41\end{array}$ & $\begin{array}{l}623.92 \uparrow \\
\times \pm 32.42\end{array}$ & $\begin{array}{l}616.32 \\
\pm 32.03\end{array}$ & $\begin{array}{l}603.62 \\
\pm 30.87\end{array}$ & $\begin{array}{l}621.33 \\
\pm 27.43\end{array}$ & $\begin{array}{l}612.50 \\
\pm 27.86\end{array}$ & $\begin{array}{l}612.68 \\
\pm 29.89\end{array}$ & $\begin{array}{l}610.92 \\
\pm 32.03\end{array}$ & $\begin{array}{l}592.31 \downarrow \\
\times \pm 31.25\end{array}$ & $\begin{array}{l}605.26 \\
\pm 28.25\end{array}$ & $\begin{array}{c}599.96 \downarrow \\
\pm 32.62\end{array}$ & $\begin{array}{l}610.75 \\
\pm 32.06\end{array}$ & $12.20^{*}$ \\
\hline $\begin{array}{l}\text { S } \\
\text { [number] }\end{array}$ & $\begin{array}{l}0.81 \downarrow^{x} \\
\pm 1.04\end{array}$ & $\begin{array}{l}0.54 \downarrow^{\sharp} \\
\pm 0.75\end{array}$ & $\begin{array}{l}0.84 \downarrow^{x} \\
\pm 1.00\end{array}$ & $\begin{array}{c}1.54 \\
\pm 1.45\end{array}$ & $\begin{array}{c}1.49 \\
\pm 1.27\end{array}$ & $\begin{array}{c}0.63 \\
\pm 0.71\end{array}$ & $\begin{array}{l}1.89 \uparrow^{x} \\
\pm 1.45\end{array}$ & $\begin{array}{c}1.22 \\
\pm 1.37\end{array}$ & $\begin{array}{l}1.92 \uparrow^{\times} \\
\pm 1.44\end{array}$ & $\begin{array}{l}1.89 \uparrow^{x} \\
\pm 1.67\end{array}$ & $\begin{array}{l}1.99 \uparrow^{x} \\
\pm 1.72\end{array}$ & $\begin{array}{c}1.28 \\
\pm 1.38\end{array}$ & $21.23^{*}$ \\
\hline $\begin{array}{l}\text { PN } \\
\text { [number] }\end{array}$ & $\begin{array}{l}51.05 \uparrow^{x} \\
\pm 20.29\end{array}$ & $\begin{array}{l}53.90 \uparrow^{x} \\
\pm 19.93\end{array}$ & $\begin{array}{l}50.30 \uparrow \\
\pm 22.20\end{array}$ & $\begin{array}{l}37.29 \downarrow^{x} \\
\pm 13.93\end{array}$ & $\begin{array}{c}47.67 \\
\pm 23.03\end{array}$ & $\begin{array}{l}68.63 \uparrow^{\sharp} \\
\pm 30.07\end{array}$ & $\begin{array}{r}49.69 \\
\pm 24.19\end{array}$ & $\begin{array}{l}33.89 \downarrow^{x} \\
\pm 12.30\end{array}$ & $\begin{array}{l}31.75 \downarrow^{\sharp} \\
\pm 12.85\end{array}$ & $\begin{array}{c}40.72 \\
\pm 16.42\end{array}$ & $\begin{array}{l}33.29 \downarrow^{x} \\
\pm 12.66\end{array}$ & $\begin{array}{c}43.69 \\
\pm 20.18\end{array}$ & $30.38^{*}$ \\
\hline PA [\%] & $\begin{array}{c}77.19 \\
\pm 11.07\end{array}$ & $\begin{array}{c}81.07 \uparrow^{x} \\
\pm 8.25\end{array}$ & $\begin{array}{l}78.08 \uparrow \\
\pm 11.09\end{array}$ & $\begin{array}{l}71.51 \downarrow \\
\pm 12.08\end{array}$ & $\begin{array}{l}79.32 \uparrow^{x} \\
\pm 9.61\end{array}$ & $\begin{array}{c}83.56 \uparrow^{\sharp} \\
\pm 7.89\end{array}$ & $\begin{array}{l}79.53 \\
\pm 9.64\end{array}$ & $\begin{array}{l}68.80 \downarrow^{x} \\
\pm 12.41\end{array}$ & $\begin{array}{c}72.63 \\
\pm 11.58\end{array}$ & $\begin{array}{c}74.93 \\
\pm 10.64\end{array}$ & $\begin{array}{l}70.81 \downarrow^{x} \\
\pm 10.94\end{array}$ & $\begin{array}{c}75.14 \\
\pm 11.71\end{array}$ & $18.13^{*}$ \\
\hline $\begin{array}{l}\mathrm{D} \\
\text { [number] }\end{array}$ & $\begin{array}{l}20.59 \\
\pm 6.71\end{array}$ & $\begin{array}{l}19.68 \\
\pm 6.49\end{array}$ & $\begin{array}{l}20.51 \\
\pm 6.57\end{array}$ & $\begin{array}{c}18.51 \downarrow \\
\pm 6.35\end{array}$ & $\begin{array}{l}19.84 \\
\pm 6.10\end{array}$ & $\begin{array}{l}16.96 \\
\pm 7.34\end{array}$ & $\begin{array}{l}21.35 \\
\pm 6.49\end{array}$ & $\begin{array}{l}19.11 \\
\pm 7.14\end{array}$ & $\begin{array}{l}20.90 \\
\pm 6.88\end{array}$ & $\begin{array}{l}22.15 \\
\pm 6.84\end{array}$ & $\begin{array}{l}22.33 \\
\pm 8.54\end{array}$ & $\begin{array}{l}20.33 \\
\pm 6.92\end{array}$ & $4.78^{*}$ \\
\hline DW [\%] & $\begin{array}{c}51.65 \\
\pm 11.80\end{array}$ & $\begin{array}{c}54.47 \\
\pm 10.45\end{array}$ & $\begin{array}{l}53.02 \uparrow \\
\pm 11.34\end{array}$ & $\begin{array}{c}49.08 \\
\pm 12.99\end{array}$ & $\begin{array}{c}49.15 \\
\pm 14.40\end{array}$ & $\begin{array}{c}53.99 \\
\pm 14.58\end{array}$ & $\begin{array}{c}49.18 \\
\pm 12.00\end{array}$ & $\begin{array}{c}48.20 \\
\pm 12.78\end{array}$ & $\begin{array}{c}47.24 \\
\pm 11.83\end{array}$ & $\begin{array}{l}45.30 \downarrow^{x} \\
\pm 11.36\end{array}$ & $\begin{array}{c}47.85 \\
\pm 11.67\end{array}$ & $\begin{array}{c}50.00 \\
\pm 12.31\end{array}$ & $6.97^{*}$ \\
\hline $\begin{array}{l}\text { C } \\
\text { [number] }\end{array}$ & $\begin{array}{l}0.93 \downarrow^{x} \\
\pm 1.80 \\
\end{array}$ & $\begin{array}{c}1.00 \\
\pm 1.64 \\
\end{array}$ & $\begin{array}{l}0.60 \downarrow^{*} \\
\pm 1.35 \\
\end{array}$ & $\begin{array}{l}2.80 \uparrow^{\times} \\
\pm 2.58 \\
\end{array}$ & $\begin{array}{c}1.78 \\
\pm 2.26 \\
\end{array}$ & $\begin{array}{c}0.75 \\
\pm 1.57 \\
\end{array}$ & $\begin{array}{c}1.64 \\
\pm 2.06 \\
\end{array}$ & $\begin{array}{l}2.88 \uparrow^{x} \\
\pm 2.29 \\
\end{array}$ & $\begin{array}{l}2.90 \uparrow^{x} \\
\pm 2.76 \\
\end{array}$ & $\begin{array}{c}1.98 \\
\pm 2.27\end{array}$ & $\begin{array}{l}3.04 \uparrow^{x} \\
\pm 2.70\end{array}$ & $\begin{array}{c}1.80 \\
\pm 2.34\end{array}$ & $29.61^{*}$ \\
\hline \multicolumn{14}{|c|}{$\begin{array}{c}\text { Statistically significant differences: } \uparrow>\bar{x} \downarrow \downarrow<\bar{x}(p \leq 0.001), * \text { Statistically significant } F(p \leq 0.001), \\
\bar{x} \text {-arithmetic mean for all Midfielders; Effect size: }{ }^{*} \text { - large, }{ }^{x} \text { - medium }\end{array}$} \\
\hline
\end{tabular}




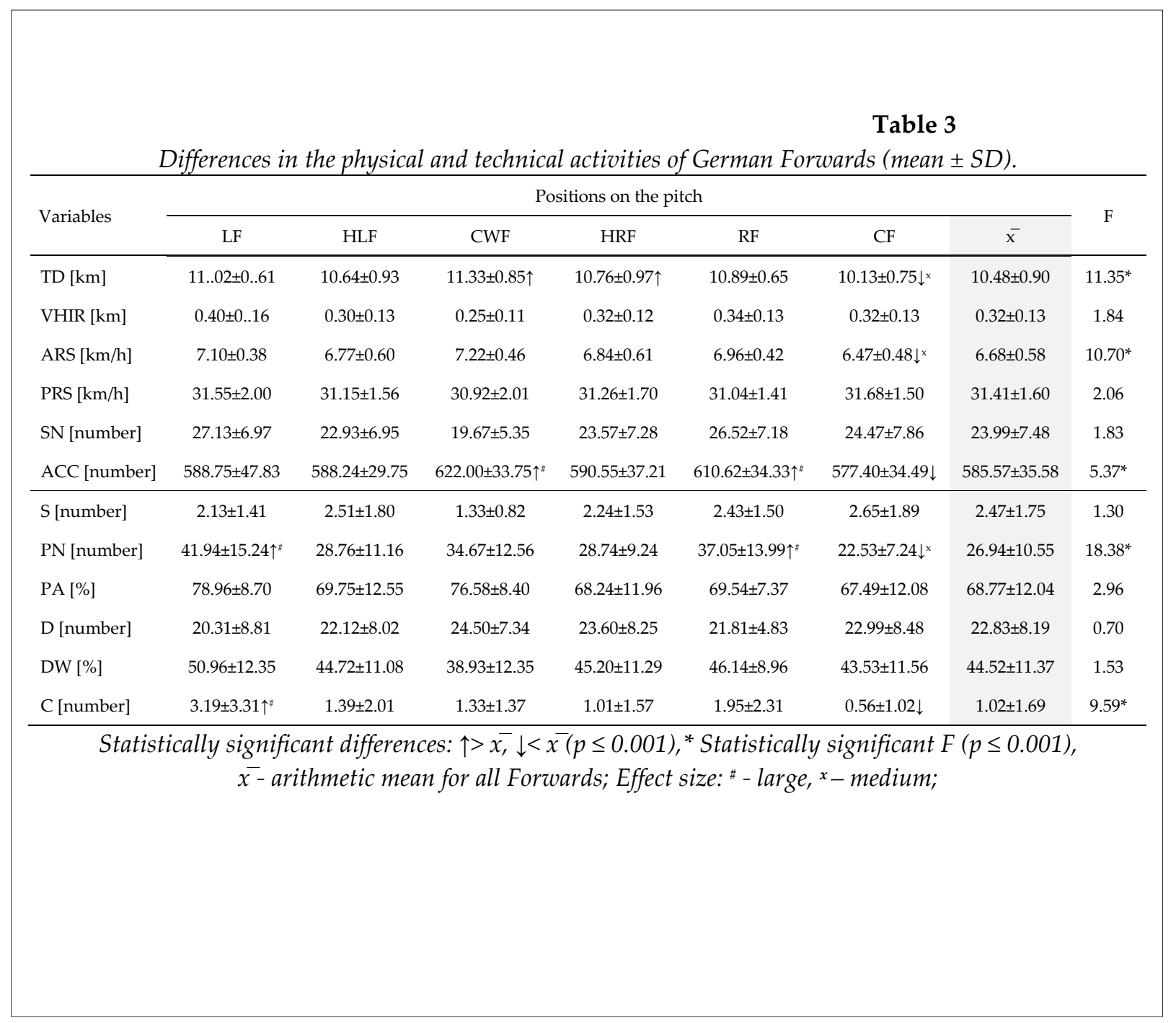

\section{Defenders}

Statistical analysis of physical activities in relation to positions on the pitch revealed a large effect size for TD among RFBs $(\mathrm{d}=0.69)$; for $\underline{\mathrm{VHIR}}$ among LFBs $(\mathrm{d}=0.73)$ and CLDs $(\mathrm{d}=0.67)$; for ARS among RFBs $(\mathrm{d}=0.70)$; and for $\underline{\mathrm{SN}}$ among LFBs $(\mathrm{d}$ $=0.88)$ and RFBs $(\mathrm{d}=0.72)$. Furthermore, technical activities included a large effect size for $\underline{\mathrm{C}}$ among LFBs $(\mathrm{d}=0.76)$ and CRDs $(\mathrm{d}=0.82)($ Table 1$)$. Midfielders

The statistical analysis of the physical activities in relation to positions on the pitch found large effect sizes for VHIR among DMCs $(\mathrm{d}=1.05)$, DMRs $(\mathrm{d}=0.73)$, CMs $(\mathrm{d}=1.20)$, RWMs $(\mathrm{d}=0.77)$ and OMRs $(\mathrm{d}=0.80)$; for $\underline{\text { PRS }}$ among RWMs $(\mathrm{d}=$ $0.68)$ and OMRs $(\mathrm{d}=0.71)$; and for $\underline{\mathrm{SN}}$ among DMCs $(\mathrm{d}=0.97)$, DMRs $(\mathrm{d}=0.76)$, LWMs $(\mathrm{d}=0.67), \mathrm{CMs}(\mathrm{d}=1.43)$, RWMs $(\mathrm{d}=0.72)$ and OMRs $(\mathrm{d}=0.84)$. Furthermore, analysis of technical activity again revealed major effects for $\underline{S}$ among DMCs $(\mathrm{d}=0.69)$; for $\underline{\mathrm{PN}}$ among CMs $(\mathrm{d}=0.99)$ and OMLs $(\mathrm{d}=0.72)$; for PA among CMs $(\mathrm{d}=0.86)$; and for $\underline{C}$ among DMRs $(\mathrm{d}=0.65)$ (Table 2$)$.

Forwards

Statistical analysis of physical activities in relation to the position on the pitch showed a large effect size in the case of ACC, among CWFs ( $d=$ $1.05)$ and RFs $(\mathrm{d}=0.72)$. Furthermore, analysis of technical activities showed a large effect for $\underline{\mathrm{PN}}$ among LFs $(\mathrm{d}=1.16)$ and RFs $(\mathrm{d}=0.82)$, as well as

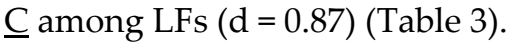

\section{Discussion}

The evolutionary trend in soccer is towards individualised physical and technical preparation of players. The research presented here is novel in that physical and technical activities of professional players at 22 different 
positions on the pitch have been considered, with the study aiming to examine how positions affected those activities. We also attempted to determine what features might be used to differentiate between and identify the activities within the Defender, Midfielder and Forward formations.

\section{Defenders}

\section{Activities not distinguishing Defenders}

One of the study's main findings was that soccer players in the formation comprising Defenders did not differ significantly in terms of the number of accelerations (ACC), the number of shots (S) or the percentage of duels won (DW). Thus, notwithstanding much-described differences in physical and technical activities of left, right or central Defenders (Bradley et al., 2013), these were found to be equally important variables for all Defenders. The number of accelerations (ACC) relates to a short lived increase in speed across each individual box for at least $1.5 \mathrm{~s}-\mathrm{a}$ recording that was previously limited by technological issues. However, as players in a typical match are likely to perform 150-250 different actions, as well as 1100 changes of direction, ACC seems essential where different types of duels with opponents need to be won (Andrzejewski et al., 2018). The importance of this variable for all players in defence can therefore come as no surprise. Less intuitive was the lack of differentiation between Defenders in relation to reported values for shots or typically offensive activity. In modern soccer, Fullbacks often play offensively to improve the match result by using side sectors of the pitch (Andrzejewski et al., 2018). However, our research also made it clear that Fullbacks were most often Central Defenders (CDs), and their role was more linked with assisting than taking shots. The percentage of duels won (DW) would seem to represent key activity for players in defence, and this idea has been confirmed by the steady, evolutionary expansion of such activities in successive seasons of the Germans' Bundesliga (Link and Lorenzo, 2016).

Activity distinguishing Defenders

The Left and Right Fullbacks differed from other Defenders in covering greater total distances (TD) in the course of a match, as well as greater distances covered at very high intensity (VHIR). They also completed a greater number of sprints (SN) and maintained a higher average running speed (ARS). The results here thus confirm earlier conclusions that the absolute number of explosive activities and sprints in match play is position-related, with players playing down the sides of the field most capable of speed-play (Bradley et al., 2013; Bush et al., 2015). This may be because players recruited to these positions are more adept at the "explosive" activities needed in line with the today's teams' style of game played and tactical systems applied (Bradley et al., 2009; Bush et al., 2015). Furthermore, Bundesliga players in Fullback positions, and in possession of the ball, cover significantly greater distances while sprinting in won matches, as opposed to the lost ones (Andrzejewski et al., 2018).

However, a high dynamic to physical activity among Fullbacks did not correlate positively with technical activity, with these players differing from Central Defenders in that they made around 3-4 fewer passes (PN) on average, and achieved 9-10\% lower pass accuracy (PA). While high-intensity movement is a key aspect of today's game (Carling, 2013), the phenomenon of fewer passes of more limited effectiveness is not favourable since, statistically, one more pass made down the sides of the pitch by a player in the course of a match was associated with a $3.3 \%$ greater chance of that player's team winning a given match.

Midfielders

Activity not distinguishing between Midfielders

Midfielders were the formation comprising the greatest number of occupied pitch positions (with 11 such positions revealed by the Impire AG motion analysis system). The interpretation of activity in line with individual playing positions, as opposed to the formation as a whole, thus seems fully justified (Bradley et al., 2009). Nevertheless, Midfielders engaged in match activity at a level similar among all of that formation's players. For example, there was no significant differentiation regarding total distance covered (TD), average running speed (ARS), the number of accelerations (ACC), the number of duels (D), or the percentage of duels won (DW). This is very interesting information in the context of a study by Konefał et al. (2018), which reported a very strong link between ARS among Midfielders and the subsequent match outcome. Statistically, an increase in the average value of the latter variable equal to $0.1 \mathrm{~km} / \mathrm{h}$ is equivalent to 
$15.7 \%$ greater chances of victory among Wide Midfielders and $10 \%$ greater chances among Central Midfielders (Konefał et al., 2018). In contrast, when TD is concerned, there is a surprising lack of differences between positions, perhaps because the TD Midfielders cover mainly consists of low-intensity effort reducing team's chances of victory (Konefał et al., 2018). ACC and DW are important elements of the game played in this formation, in the same way as for Defenders. Among other things, all Midfielder-formation players seeking to pose a threat to their opponents should therefore be mobile (more than representatives of other formations, with an average per match of $11.27 \pm 0.73 \mathrm{~km}$ ). They should also produce many dynamic movements of short duration, and also engage in position-specific activities.

\section{Activities distinguishing between Midfielders}

Our research shows that, in comparison with Midfielders in general, Defensive Midfielders (categories DML, DMC and DMR), but also Central Midfielders (CMs) cover shorter distances at very high intensity (VHIR), also performing a smaller number of sprints (SN) and attaining a lower peak running speed (PRS). It confirms findings of Andrzejewski et al. (2018), i.e. that, in defensive play, Central Midfielders perform significantly fewer sprints and run shorter sprint distances, while high-intensity activity of players occurs more often in the offensive game. This is in line with our work, since activities of Offensive Midfielders (OML and OMR) and Wide Midfielders (LWM and RWM) assume a direction opposite to that noted for Defensive Midfielders. Of all today's soccer players, Wide Midfielders cover the greatest distances at high intensity during a match (Bradley et al., 2009; Chmura et al., 2018). In the Premier League and Championship League, these distances are of $883 \pm 170 \mathrm{~m}$ and 1095 $\pm 168 \mathrm{~m}$, respectively. These are higher values than those noted for Central Midfielders, on average by 147 and $281 \mathrm{~m}$, respectively (Bradley et al., 2013). A similar relationship can be noted in sprints, with Wide Midfielders in the Championship League found to sprint distances greater by $92 \%$ than those covered by Central Defenders (Bradley et al., 2013).

Analysis of technical activities distinguishing between Midfielders revealed that Defensive Midfielders (DML, DMC, DMR) and
Central Midfielders (CM) completed fewer shots (S) and crosses (C), as well as a larger number of passes $(\mathrm{PN})$, with greater pass accuracy (PA). As with physical activities, technical activities also assumed values that were in the opposite direction among Offensive Midfielders (OML and OMR), as well as Wide Midfielders (LWM and RWM). Our work confirms what has been revealed hitherto, while also indicating that the formation that takes the most shots in Bundesliga matches includes Wide Midfielders as well as OML and OMR Midfielders. This is valuable information, given that differences between winning and losing teams in the professional game are mainly visible in the number and effectiveness of shots at goal, i.e. tasks assigned to offensive Midfielders (Castellano et al., 2012; Liu et al., 2015). A greater number of passes (PN) reported in this study, with greater pass accuracy (PA) among DML, DMC, DMR and CM players, has been also observed by many other authors. The greatest number of passes with the highest accuracy are attributes of Central Midfielders (Bradley et al., 2013), with their activities linked significantly with the overall success of the team (Lago-Penas and LagoBallesteros, 2011; Liu et al., 2015; Shafizadeh et al., 2013). In the course of the 2010 World Championships, $17.93 \%$ of goals were scored following shots from outside the penalty area (Njororai, 2013). For this reason, the large number of (mostly highly-effective) passes performed by Defensive and Central Midfielders may potentially give rise to the high-quality shots taken by Wide and Offensive Midfielders (Clemente et al., 2013).

Our research shows that HLM, HRM and OMC Midfielders maintain their physical and technical activity at an average level for the Midfielder formation as a whole. In general, these players would appear to need to be the most universal of the Midfielders, in order for them to adjust to playing at any position within the formation.

Forwards

Activities distinguishing between Forwards

Forwards constitute the most uniform formation. With regard to WHIR, PS and SN, it is not possible to differentiate between players playing in this formation. The value with reference to high-speed efforts in today's game of soccer has already been provided. However, among Forwards, this capacity is still of greater 
importance, since most goals are scored following dynamic actions these players undertake (Njororai, 2013). In this context, it is worth adding that, from the physical activity point of view, the sprint is one of soccer's most important activities, even though it accounts on average for just between 1 and $12 \%$ of the average distance a player covers during a match (Dellal et al., 2011).

Andrzejewski et al. (2018) and Chmura et al. (2018) have shown that sprints and highintensity running among Forwards are crucial to the team's success. Moreover, the increase of game intensity continues, with the last decade bringing a $30-50 \%$ increase in the distances covered at high intensity or while sprinting in matches in the English Premier League. Furthermore, the number of passes has likewise risen by $40 \%$ during this period. It therefore comes as no real surprise that Forwards may not be distinguished with respect to S, PA, D or DW.

Many studies concerning soccer have focused, not only on numbers of shots, but also on the way goals are scored (Rein et al., 2017). It would seem that a high value for $S$ is achieved on the basis of the high percentage PA, D number and percentage value for DW recorded among all Forwards. Both the number of passes and passing effectiveness correlate positively with the match outcome, with players in all positions making the greatest numbers of passes, and achieving the highest pass accuracy, in won matches (Bradley et al., 2013). The results indicate that the number of shots represents important activity for Forwards, albeit supplemented by effective passes and duels, given that effectiveness of technical activities is more correlated with the match outcome than the mere numbers of given kinds of activity (Liu et al., 2015).

\section{Activities distinguishing Forwards}

Our research indicates that CF players, whose physical and technical activities resembled those of other kinds of Forwards, differed from them in covering a significantly shorter TD, with lower ARS and a smaller PN. Konefał et al. (2018) showed that a lower distance covered in the first half by Forwards proved favourable to the match outcome, while average running speed was very important for Forwards, given that even a $0.1 \mathrm{~km} / \mathrm{h}$ increase in this variable, in the second half of a match, is sufficient to increase the chances of victory of these Forwards' team by as much as $27 \%$.
Bearing in mind the smaller number of passes CF players are responsible for, the key role in playing the ball would seem to be assigned to other positions, since passes from the mid-field into the attacking area prove most effective in modern soccer (Rein et al., 2017).

\section{Conclusions}

Our results revealed significant differences in levels of physical and technical activities among players in the same formations, yet occupying different positions on the pitch. Equally, it was also possible to identify many activities of which level did not differ across a formation, despite differences of positions. In each formation, players having more offensive tasks to perform engaged in more explosive activities at very high intensity. Moreover, while shots were important for them, they passed less, and achieved a lower level of passing effectiveness. In turn, players assigned more-defensive tasks pursued activities at a lower level of intensity, although with a greater number of passes, and a higher percentage for passing effectiveness. Irrespective of either formation or position on the pitch, very important activities in the contemporary game of soccer are ACC, as well as the number of duels engaged in and player's effectiveness.

The detailed analysis of results and discussion of supplementary information on the physical and technical activities of soccer players revealed a similar level of activity of players playing in certain positions, and thus provided a basis for regrouping players in relation to five new formations, i.e.:

Formation I - players playing in the central defensive zone (the CLD, CD and CRD positions) and Defenders playing in the central midfield zone (in positions DML, DMC, DMR and CM) - the features characteristic here are a large number of passes, which also achieve a high level of effectiveness, as well as low-intensity physical activity and a large number of ACCs; Formation II - players playing in the side zones of the pitch (in positions LFB, RFB, LWM, RWM, OML, OMR, LF and $\mathrm{RF}$ ) - the characteristic features are a small number of passes (often of limited effectiveness), a large number of crosses, high-intensity physical activities and a large number of sprints; Formation III - offensive players playing in the central part of the midfield (in positions HLM, HRM and OMC) - 
these are universal Midfielders, with physical and technical activities at levels close to the average for the formation as a whole; Formation IV - players playing in the central zone of attack (in the HLF, CWF and HRF positions) - displaying a high number of activities at high intensity and high effectiveness in technical activities; Formation V $\mathrm{CF}$ - features of the kind seen in all Forwards, with a shorter TD covered, more limited ARS and lower $\mathrm{PN}$, albeit with a high level of effectiveness for their passes.

\section{References}

Andrzejewski M, Chmura P, Konefał M, Kowalczuk E, Chmura J. Match outcome and sprinting activities in match play by elite German soccer players. J Sports Med Phys Fitness, 2018; 58(6): 785-792

Bradley PS, Archer DT, Hogg B, Schuth G, Bush M, Carling C, Barnes C. Tier-specific evolution of match performance characteristics in the English Premier League: it's getting tougher at the top. J Sports Sci, 2016; 34(10): 980-987

Bradley PS, Lago-Penas C, Rey E, Gomez Diaz A. The effect of high and low percentage ball possession on physical and technical profiles in English FA Premier League soccer matches. J Sports Sci, 2013; 31(12): 1261-1270

Bradley PS, Sheldon W, Wooster B, Olsen P, Boanas P, Krustrup P. High-intensity running in English FA Premier League soccer matches. J Sports Sci, 2009; 27(2): 159-168

Bush M, Barnes C, Archer DT, Hogg B, Bradley PS. Evolution of match performance parameters for various playing positions in the English Premier League. Hum Mov Sci, 2015; 39: 1-11

Carling C. Interpreting physical performance in professional soccer match-play: should we be more pragmatic in our approach? Sports Med, 2013; 43(8): 655-663

Castellano J, Casamichana D, Lago C. The Use of Match Statistics that Discriminate Between Successful and Unsuccessful Soccer Teams. J Hum Kinet, 2012; 31: 139-147

Chmura P, Andrzejewski M, Konefał M, Mroczek D, Rokita A, Chmura J. Analysis of Motor Activities of Professional Soccer Players during the 2014 World Cup in Brazil. J Hum Kinet, 2017; 56: 187-195

Chmura P, Konefał M, Chmura J, Kowalczuk E, Zając T, Rokita A, Andrzejewski M. Match outcome and running performance in different intensity ranges among elite soccer players. Biol Sport, 2018; 35(2): 197-203

Clemente FM, Couceiro MS, Martins FM, Ivanova MO, Mendes R. Activity profiles of soccer players during the 2010 world cup. J Hum Kinet, 2013; 38: 201-211

Cohen J. Statistical Power Analysis for the Behavioral Sciences. Hillsdale, NJ: Lawrence Erlbaum Associates; 1988

Dellal A, Chamari K, Wong DP, Ahmaidi S, Keller D, Barros R, Bisciotti GN, Carling C. Comparison of physical and technical performance in European soccer match-play: FA Premier League and La Liga. Eur J Sport Sci, 2011; 11(1): 51-59

DFL. Definitions for Official Gama Data. Frankfurt; 2014

Di Salvo V, Pigozzi F, Gonzalez-Haro C, Laughlin MS, De Witt JK. Match performance comparison in top English soccer leagues. Int J Sports Med, 2013; 34(6): 526-532

Hoppe MW, Slomka M, Baumgart C, Weber H, Freiwald J. Match Running Performance and Success Across a Season in German Bundesliga Soccer Teams. Int J Sports Med, 2015; 36(7): 563-566

Konefał M, Chmura P, Kowalczuk E, Figueiredo AJ, Sarmento H, Rokita A, Chmura J, Andrzejewski M. Modeling of relationships between physical and technical activities and match outcome in elite German soccer players. J Sports Med Phys Fitness, 2018; doi: 10.23736/S0022-4707.18.08506-7. [Epub ahead of print]

Konefał M, Chmura P, Andrzejewski M, Pukszta D, Chmura J. Analysis of match performance of full-backs from selected European soccer leagues. Cent. Eur. J. Sport Sci. Med., 2015; 11(3): 45-53 
Krustrup P, Mohr M, Ellingsgaard H, Bangsbo J. Physical demands during an elite female soccer game: importance of training status. Med Sci Sports Exerc, 2005; 37(7): 1242-1248

Lago-Penas C, Lago-Ballesteros J. Game location and team quality effects on performance profiles in professional soccer. J Sports Sci Med, 2011; 10(3): 465-471

Link D, Lorenzo MF. Seasonal Pacing - Match Importance Affects Activity in Professional Soccer. PLoS One, 2016; 11(6): e0157127

Liu H, Gomez MA, Lago-Penas C, Sampaio J. Match statistics related to winning in the group stage of 2014 Brazil FIFA World Cup. J Sports Sci, 2015; 33(12): 1205-1213

Liu H, Hopkins W, Gómez AM, Molinuevo SJ. Inter-operator reliability of live football match statistics from OPTA Sportsdata. Int J Perform Anal Sport, 2013; 13(3): 803-821

Mackenzie R, Cushion C. Performance analysis in football: a critical review and implications for future research. J Sports Sci, 2013; 31(6): 639-676

Maszczyk A, Roczniok R, Waśkiewicz Z, Czuba M, Mikołajec K, Zajac A, Stanula A. Application of regression and neural models to predict competitive swimming performance. Percept Mot Skills, 2012; 114(2): 61026

Maszczyk A, Golas A, Czuba M, Krol H, Wilk M, Stastny P, Goodwin J, Kostrzewa M, Zajac A. EMG Analysis and Modelling of Flat Bench Press Using Artificial Neural Networks. SAJRPER. 2016; 38(1): 91-103

Njororai S. Analysis of goals scored in the 2010 World Cup soccer tournament held in South Africa. J Phys Edu Sport, 2013; 13(1): 6-13

Rein R, Raabe D, Memmert D. "Which pass is better?" Novel approaches to assess passing effectiveness in elite soccer. Hum Mov Sci, 2017; 55: 172-181

Shafizadeh M, Taylor M, Penas CL. Performance consistency of international soccer teams in Euro 2012: a time series analysis. J Hum Kinet, 2013; 38: 213-226

Siegle M, Stevens T, Lames M. Design of an accuracy study for position detection in football. J Sports Sci, 2013; 31(2): 166-172

Tiedemann T, Francksen T, Latacz-Lohmann U. Assessing the performance of German Bundesliga football players: a non-parametric metafrontier approach. Cent Eur J Oper Res, 2011; 19(4): 571-587

Wallace JL,Norton KI. Evolution of World Cup soccer final games 1966-2010: game structure, speed and play patterns. J Sci Med Sport, 2014; 17(2): 223-228

Wright C, Atkins S, Jones B, Todd J. The role of performance analysts within the coaching process: Performance Analysts Survey 'The role of performance analysts in elite football club settings. Int J Perform Anal Sport, 2013; 13(1): 240-261

\section{Corresponding author:}

\section{Pawel Chmura}

Department of Team Games, University School of Physical Education, Wrocław, ul. I.J. Paderewskiego 35, Wrocław, Poland,

Email: pawel.chmura@awf.wroc.pl,

Phone: +48 713473564 